\title{
Electromotive Force in Electrochemical Modification of Mudstone
}

\author{
Dong Wang ${ }^{1,2}$, Jiancheng Song ${ }^{1}$ and Tianhe Kang 1 \\ ${ }^{1}$ Taiyuan University of Technology, Taiyuan, \\ 2Shanxi Coal Transportation and Sales Group Co.Ltd, Taiyuan,
}

China

\section{Introduction}

It is utilized in the coal-mine soft rock roadway that bolt with wire mesh, grouting and guniting combined supporting technique and quadratic supporting technique. The supporting techniques can anchor high stressed soft rock and jointed soft rock, however, with little help for mudstone. The analyses of deformable mechanism in mudstone roadway are based on engineering mechanical property of mudstone, which mainly includes swelling and disintegration. On the other hand, the mineralogical composition of mudstone is quartz, calcite, montmorillonite, illite, kaolinite, and chlorite. The analyses lead to the following conclusion: engineering mechanical property of mudstone induced by the shrink-swell property of clay minerals, swelling clay minerals play significant roles in the swelling process of mudstone.

In swelling clay minerals there are two types of swelling. One is the innercrystalline swelling caused by the hydration of the exchangeable cations of the dry clay; the other is the osmotic swelling resulted from the large difference in the ion concentrations close to the clay surfaces and in the pore water. The swelling of clay minerals as it manifests itself in the coalmine mudstone roadway is referred to as the osmotic swelling.

The electrochemical modification of clay minerals is that the electrodes and the electrolyte solutions modify clay minerals under electromotive force, leading to change in the physical, chemical and mechanical properties of clay minerals. Electrochemical modification of clay minerals was applied in soil electrochemistry (Adamson et al., 1967; Harton et al., 1967; Chukhrov, 1968; Gray, 1969), electrical survey (Aggour \& Muhammadain, 1992; Aggour et al., 1994), stabilization of sedimentary rock (Titkov, 1961; Titkov., 1965), and mineral processing (Revil \& Jougnot, 2008). According to the applications, the mechanism of electrochemical modification of clay minerals is summarized as follow (Adamson et al., 1966; Harton et al., 1967):

- electroosmotic dewatering and stabilization;

- cation substitutions, structures and properties change, forming new minerals.

After electromotive force treatment, the main analyses of properties centralize into the physicochemical and mechanical properties. Physicochemical and mechanical properties of mudstone changed through electrochemical modification, the modified purpose to change other unfavorable properties of mudstone, such as mechanical property (uniaxial 
compressive strength, tensile strength, and triaxial compressive strength) and engineering mechanical property (plasticity, swelling, rheology and disturbance characteristics).

With respect to the modification of mudstone by electrochemical method, the essence of the method is electrochemical modification of physicochemical properties of clay minerals. It is our destination task that the conventional electrochemical stabilization of clay minerals may be applied to support mudstone roadway in coal-mine.

\section{Electrochemical dewatering and stabilization}

Under electromotive force treatment, electrochemical dewatering and stabilization is based on the electrically induced flow (namely, electroosmosis) of water trapped between the particles of clay minerals. Such electrically induced flow is possible because of the presence of the electrical double layer at the solid/liquid interface.

\subsection{Electroosmosis and electrolysis phenomenon}

Electroosmosis is the motion of ionized liquid relative to the stationary charged surface by an applied DC fields. It should be emphasized that electroosmotic dewatering is most attractive when the water is trapped between fine-grained clay particles.

In 1808 the discovery of electroosmosis phenomenon (Amirat \& Shelukhin, 2008) by Reiss occurred soon after the first investigations on the electrolysis phenomenon of water by Nicholson and Carlisle. Reiss observed that a difference in the electric potentials applied to the water in a U-tube results in a change of water levels (Fig.1) when the tube is filled partially with thin sand.

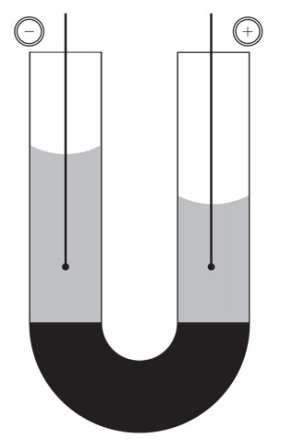

Fig. 1. Electroosmosis (Amirat \& Shelukhin, 2008).

According to the surface charge properties of the clay minerals, fine-grained clay particles present in sedimentary rock normally net negative electric charges, whereas groundwater is the electrolyte solutions in nature. On the surfaces of fine-grained clay particles there exists an excess of negative charges, forming the electrical double layer. The inner or Stern layer consists of negative ions adsorbed onto the solid surface through electrostatic and Van Der Waals' forces, the ions and the oppositely charged ions in the absorbed layer do not move. The outer diffuse or Gouy layer is formed by oppositely charged ions under the influence of ordering electrical and disordering thermal forces, the positively charged ions can move.

In the presence of electromotive force in conjunction with addition of the electrolyte solutions, the electrical conductivity of clay soils increases. The assumption is as follows: 
an external electric field is parallel to the solid-liquid interface in the capillary. Positive ions being formed in great quantities by the action of the electric current move in the direction of the cathode and carry with water molecules to which they are attached. The velocity of the electrolyte solutions in the electrical double layer is described by the relationship:

$$
\mathrm{v}=\varepsilon \mathrm{E} \zeta / \eta
$$

where $\varepsilon$ is the dielectric constant; $\mathrm{E}$ is the electromotive force; $\zeta$ is the zeta potential as the potential difference in the electrical double layer; $\eta$ is the viscosity of the electrolyte solutions.

The electroosmotic velocity under the unit electric field intensity can be written as:

$$
\mathrm{V}_{\mathrm{e}}=\mathrm{v} / \mathrm{E}=\varepsilon \zeta / \eta
$$

In the capillary, the thickness of the electrical double layer is negligible with respect to the capillary radius, most of the fluid in the capillary moves with a velocity. The electroosmotic velocity can be given by:

$$
\mathrm{v}_{\mathrm{e}}=\mathrm{K}_{\mathrm{e}} \partial \mathrm{E} / \partial \mathrm{L}
$$

where $\mathrm{K}_{\mathrm{e}}=\varepsilon \zeta / 4 \Pi \eta$ is the electroosmotic coefficient; $\partial \mathrm{E} / \partial \mathrm{L}$ is the electromotive force gradient; $\mathrm{L}$ is the distance between the two electrodes.

Fine-grained clay particles are negatively charged mostly because of cation substitutions. The charge is balanced by exchangeable cations adsorbed to the surfaces of clay minerals. The internal balance of charges is incorporated in the electrical double layer. Potassium and sodium cations contained in the outer diffuse layer are substituted by electrically stronger hydrogen, calcium, and aluminum cations. The substitution leads to a decrease in the thickness of water film on the clay particles and to a considerable decrease in hydrophilic tendency of the clays. Thus, the size of some of the clay particles decreases. Decrease in size and charge of the particles results in coagulation, crystallization, and adsorption of small particles on the surfaces of the larger ones. Coagulation and crystallization are very important in the whole electroosmotic processes.

During the electroosmotic processes, the electrolyte solutions in the vicinity of the electrodes are electrolyzed. Oxidation occurs at the anode, oxygen gas is evolved by hydrolysis. Reduction takes place at the cathode, hydrogen gas evolved. The electrolysis reactions are:

$$
\begin{aligned}
& \text { At the anode } \\
& \text { At the cathode } \quad 2 \mathrm{H}_{2} \mathrm{O}-2 \mathrm{e}^{-} \rightarrow \mathrm{O}_{2}+4 \mathrm{H}^{+} \\
& 2 \mathrm{H}_{2} \mathrm{O}+2 \mathrm{e}^{-} \rightarrow \mathrm{H}_{2}+2 \mathrm{OH}^{-}
\end{aligned}
$$

As the electrolysis proceeds, the zeta potential near the anode decreases because of the decrease in $\mathrm{pH}$ caused by reaction (4). Near the cathode, the $\mathrm{pH}$ remains high during electrolysis and changes little.

The process of the electrolysis is affected by the electromotive force, the electrolyte solution, and temperature. Dewatering and stabilization resulted in several physicochemical and chemical processes which take place concurrently, there is difficultly in evaluating the contribution of each to the effectiveness of dewatering and stabilization. 


\subsection{Electroosmotic dewatering and stabilization}

Various structural clay minerals exhibit significant differences in substitute mechanism and in the ratio between permanent and induced charges. Fine-grained clay particles have negative charges resulted from ionization, ion adsorption, and cation substitutions. The main reason is cation substitutions.

The consolidation theory by Terzaghi has connected with electrochemical stabilization of clay minerals through electroosmosis. The differential equation governing the unidirectional electroosmotic consolidation can be expressed as follows (Zhang et al., 2005):

$$
\partial \mathrm{u} / \partial \mathrm{t}=\mathrm{C}_{\mathrm{v}} \partial^{2} \mathrm{u} / \partial \mathrm{z}^{2}
$$

where $C_{v}$ is the coefficient of consolidation, $C_{v}=k / r_{w} m_{v}=(1+e) k / r_{w} a_{v} ; k$ is the coefficient of permeability; $r_{w}$ is the unit weight of water; $m_{v}$ is the coefficient of volume compressibility; $\mathrm{m}_{\mathrm{v}}=\mathrm{a}_{\mathrm{v} /(1+\mathrm{e})}, \mathrm{u}$ is the excess hydrostatic pressure ; $\mathrm{a}_{\mathrm{v}}$ is the coefficient of compressibility.

The initial and boundary conditions for the solution of equation (6) are:

$$
\begin{gathered}
\left.\mathrm{u}\right|_{\mathrm{t}=0}=\mathrm{u}_{0} \\
\left.\mathrm{u}\right|_{\mathrm{z}=0}=-\mathrm{r}_{\mathrm{W}} \mathrm{VK}_{\mathrm{e}} / \mathrm{K}_{\mathrm{h}} \\
\partial \mathrm{u} /\left.\partial \mathrm{z}\right|_{\mathrm{z}=\mathrm{H}}=0
\end{gathered}
$$

The corresponding solution of equation (6) can be given as (Zhang \& Wang, 2002):

$$
\mathrm{u}=(4 / \Pi) \mathrm{P}_{\mathrm{e}} \sum_{0}^{\infty}[1 /(2 \mathrm{n}+1)] \sin [\Pi z(2 \mathrm{n}+1) / 2 \mathrm{H}] \exp \left(-\mathrm{T}_{\mathrm{v}}(2 \mathrm{n}+1)^{2} \Pi^{2} / 4\right)-\mathrm{P}_{\mathrm{e}}
$$

where $T_{v}=c_{v} t / H^{2}=k_{h}\left(1+e_{1}\right) t / a_{v} r_{w} H^{2}, H$ is the thickness of the clay layer; $k_{h}$ is the hydraulic conductivity; $\mathrm{K}_{\mathrm{e}}$ is the coefficient of electroosmotic permeability; $\mathrm{V}$ is the compression volume, $\mathrm{P}_{\mathrm{e}}=\mathrm{r}_{\mathrm{w}} \mathrm{VK}_{\mathrm{e}} / \mathrm{k}_{\mathrm{h}}$.

The total degree of electroosmotic consolidation defined in terms of settlement can be given by:

$$
\mathrm{U}=(4 / \Pi) \mathrm{P}_{\mathrm{e}} \sin (\Pi z / 2 \mathrm{H}) \exp \left(-\mathrm{T}_{\mathrm{v}} \Pi^{2} / 4\right)-\mathrm{P}_{\mathrm{e}}
$$

In cation substitutions of clay minerals, the electrolyte solutions should include calcium chloride, aluminum sulfate, aluminum acetate or a mixture of several electrolytes, the anode should be aluminum electrode.

\section{Modification of physicochemical and mechanical property}

With respect to modification of mechanical property, the analyses of literatures lead to the following conclusions after electromotive force treatment (Adamson et al., 1966; Adamson et al., 1966; Adamson et al., 1967; Harton et al., 1967):

- The clay saturation decreased.

- Tensile load ratio values much higher than those for the materials in the natural state.

- The reduction in shrinkage crack may be considerably.

- The tensile strength and uniaxial compressive strength in mudstone increased.

- The possibility of dewatering and stabilization of clay soils by means of electromotive force. The degree of soil stabilization and course of the processes are dependent on clay content, types of clay present, and the concentration of the electrolyte solutions. 
- $\quad$ The shrinkage of mudstone flour may be insignificant.

With respect to modification of physicochemical and mechanical property, Chilingar (Chilingar, 1970) and Aggour (Aggour \& Muhammadain, 1992; Aggour et al., 1994) studied the effect of the electromotive force on the permeability of mudstone. The results are listed below:

- The permeability and wettability of cores affected by such factors as the property of the electrical double layer, the electrical conductivity of the system, the magnitude and direction of the electrical potential gradient, and the ratio of the electroosmotic to hydrodynamic water transports.

- For the mudstone full saturated with the electrolyte solutions, the greater the resistivity, the greater is the magnitude of electroosmotic transport for the same electromotive force; a linear relation exists between the applied electromotive force gradient and the electroosmotic velocity.

- During triaxial failure test, the electrokinetic coupling coefficient increased.

\section{Newly-formed minerals in clay minerals and mudstone}

The electroosmosis can indurate clay minerals and mudstone under electromotive force treatment. The electrolyte solutions diffuse through the clay minerals and mudstone by means of ionic transmission, changing its physicochemical properties and forming newly minerals. Titkov (Titkov et al., 1965) studied newly-formed minerals, which were formed by application of different electrodes in conjunction with the addition of electrolytes in the anodic, cathodic and intermediate zones. The electrolytes consisted of $0.1 \% \mathrm{Na} 2 \mathrm{SiO} 3$, saturated $\mathrm{CaSO} 4,1 \% \mathrm{AlCl} 3, \mathrm{FeCl} 2$ and $\mathrm{NaCl}$. The electrode materials were fabricated by aluminum, iron and graphite. Limonite was formed in the anodic zone, allophane and hisingerite were formed in the middle zone and allophane, lepidocrocite, hydrohematite and gibbsite were formed in the cathodic zone. Adamson (Adamson et al., 1967) performed electrochemical experiments on $100 \mathrm{ml}$ of mudstone powder, the electromotive force range from $20 \mathrm{~mA}$ to $60 \mathrm{~mA}$, and found a newly-formed mineral: hisingerite. Harton (Harton et al., 1967) performed similar experiment. With electrochemical modification of mudstone powder in conjunction with the addition of an iron electrode and a $50 \%$ concentrated electrolyte of $\mathrm{CaCl} 2$ and $\mathrm{Al} 2(\mathrm{SO} 4) 3$. Then they found that the newly-formed minerals were calcite, an unknown aluminum silicate, iron oxides and gypsum. Youell (Youell, 1960) applied electrochemical modification to the montmorillonite and discovered that the montmorillonite was being converted to a clay mineral with properties similar to chlorite. Sun hu(Sun, 2000) ran X-ray diffraction (XRD) analysis for clay minerals after electrochemical modification. He found that the crystal structure of montmorillonite in the anodic zone had little change, the major diffraction peak was weakened and the chlorite diffraction peak had completely vanished.

Scanning electron microscopy (SEM) and X-ray diffraction analyses lead to the following conclusions:

- In anodic zone of mudstone, sheet structures of clay minerals reduced, calcite vanished.

- The content of swelling clay minerals reduced.

- In intermediate and cathodic zones of mudstone, sheet structures of clay minerals increased, lots of quartzes exited. 


\section{Experimental studies}

\subsection{Experimental apparatus}

The experimental apparatus used for the electrochemical treatment is shown schematically in Fig. 2. It mainly consists of a plexiglass pipe, electrode, the mudstone sample, electrolyte,

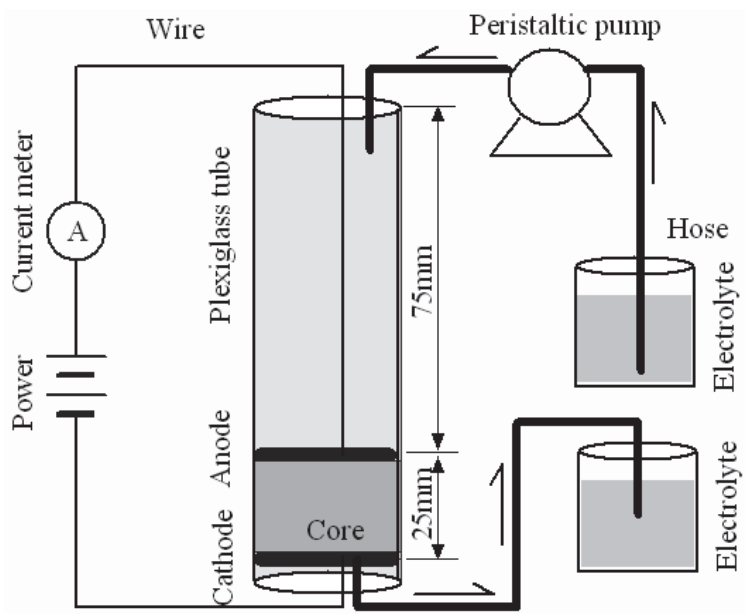

Fig. 2. Experimental apparatus.

electromotive force, current meter, peristaltic pump, hose, and wire. The electrode is a chip-type element. The anode ( $2 \mathrm{~mm}$ thick aluminium) is placed high in the plexiglass tube, whereas the cathode $(0.5 \mathrm{~mm}$ thick red copper $)$ is placed below the anode. The electrolyte consists of distilled water and $\mathrm{CaCl}_{2}$. The electromotive force provides a voltage output ranging from 0 to $250 \mathrm{~V}$ and a maximum current of $1.2 \mathrm{~A}$. The wire is an ASTVR $\Phi 0.35 \times 1 \mathrm{~mm}$ silk-covered wire. The flow range of the peristaltic BT100-1J pump is from $0.1 \mathrm{rpm}$ to $10 \mathrm{rpm}$. The pump head is an YZ1515w model. The \#13 hose is $\Phi 1.6 \times$ $2 \mathrm{~mm}$.

\subsection{Experimental sample}

The specimen which taken from the roof of the 3410 tail entry of the mine at Gaoping (in the province of Shanxi, China), was a continental clastic sedimentary rock, from the Lower Permian Shanxi formation. The specimen was sealed in the tail entry, and processed into 80 cylindrical samples, each $50 \mathrm{~mm}$ in diameter and $25 \mathrm{~mm}$ in height, which were then sealed with wax in the laboratory. An example of the X-ray diffraction patterns of the samples is shown in Fig. 3. The mineralogical composition of the sample was analysed quantitatively with an adiabatic method. The mineral content of the sample was illite $(45 \%)$, kaolinite $(10 \%)$, quartz (38\%), and anorthite $(7 \%)$. 


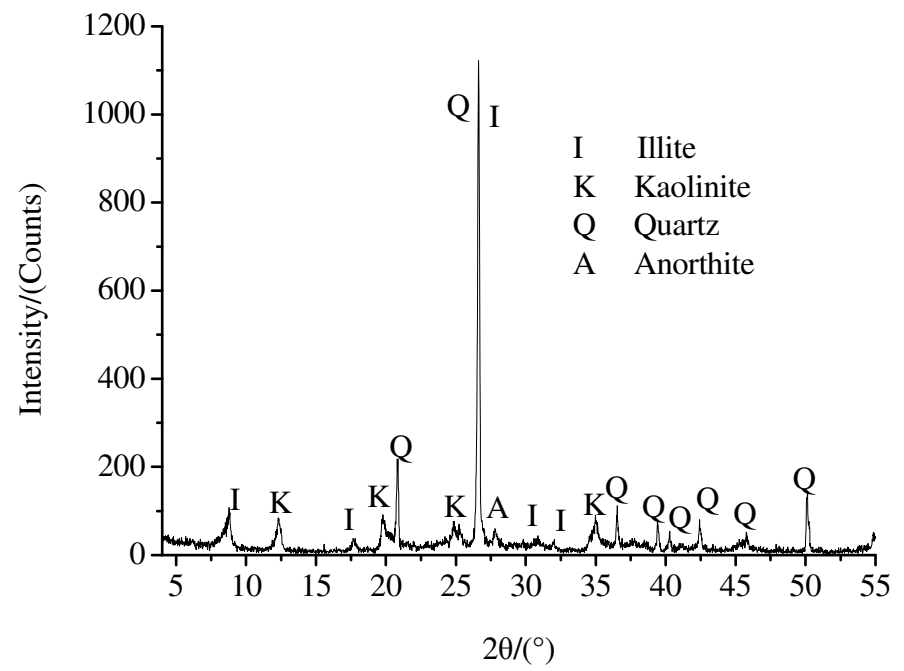

Fig. 3. X-ray diffraction pattern of experimental sample.

\subsection{Experimental scheme}

To investigate the tensile strength of the samples under different electrochemical treatments, 11 experimental schemes were designed, as shown in Table 1, and each scheme was applied to six samples. Scheme 1 was used to investigate the tensile strength of the original sample; scheme 2 was used to investigate the tensile strength with the power off and the sample submerged in distilled water; and schemes 3 11 were used to investigate the tensile strength under an electric gradient of $5 \mathrm{~V} \mathrm{~cm}^{-1}$ and at electrolyte concentrations of $0 \sim 4 \mathrm{~mol} \mathrm{~L}^{-1}$ (Wang et al., 2009).

\begin{tabular}{|c|c|c|c|}
\hline Scheme & $\begin{array}{c}\text { Electromotive force gradient } \\
\left(/ \mathrm{V} \mathrm{cm}^{-1}\right)\end{array}$ & $\begin{array}{c}\text { Electrolyte } \\
\left(/ \mathrm{mol} \mathrm{L}^{-1}\right)\end{array}$ & $\begin{array}{c}\text { Time modified } \\
(/ \mathrm{h})\end{array}$ \\
\hline 1 & - & - & - \\
\hline 2 & 0 & 0 & 120 \\
\hline 3 & 5 & 0 & 120 \\
4 & 5 & 0.05 & 120 \\
\hline 5 & 5 & 0.125 & 120 \\
\hline 6 & 5 & 0.25 & 120 \\
\hline 7 & 5 & 0.5 & 120 \\
\hline 8 & 5 & 1 & 120 \\
\hline 9 & 5 & 2 & 120 \\
\hline 10 & 5 & 3 & 120 \\
\hline 11 & 5 & 4 & 120 \\
\hline
\end{tabular}

Table 1. Experimental schemes. 


\subsection{Experimental process}

The samples were modified with the experimental apparatus shown in Fig. 2, according to the experimental schemes shown in Table 1. The Brazilian test, performed on a PC-style electro-hydraulic servo universal testing machine, was used to measure the tensile strength.

\section{Experimental studies}

Table 2 shows the measured tensile strengths of the samples. The mean tensile strength of the six original samples was $1.31 \mathrm{MPa}$ in scheme 1 . When the samples were submerged in distilled water, as in scheme 2, the mean tensile strength was $0.81 \mathrm{MPa}$, a reduction of $38.17 \%$. After modification under electromotive force gradient of $5 \mathrm{~V} \mathrm{~cm}^{-1}$ and different concentrations of the $\mathrm{CaCl}_{2}$ electrolyte, the mean tensile strength ranged from $1.53 \mathrm{MPa}$ to $2.83 \mathrm{MPa}$ in schemes $3 \sim 11$. Compared with the tensile strength in scheme 1, the mean tensile strength after the electrochemical treatment increased by $16.79 \sim 116.03 \%$.

\begin{tabular}{|c|c|c|c|c|c|c|c|}
\hline \multirow{2}{*}{ Scheme } & \multicolumn{7}{|c|}{$\begin{array}{c}\text { Measured tensile strength } \\
\text { (/MPa) }\end{array}$} \\
\hline 1 & 1.22 & 1.03 & 1.59 & 1.13 & 1.47 & 1.42 & 1.31 \\
\hline 2 & 0.81 & 0.82 & 0.85 & 0.74 & 0.74 & 0.87 & 0.81 \\
\hline 3 & 2.27 & 2.27 & 2.61 & 2.33 & 2.31 & 2.25 & 2.34 \\
\hline 4 & 2.09 & 2.04 & 2.14 & 2.11 & 2.16 & 2.11 & 2.11 \\
\hline 5 & 2.80 & 2.83 & 2.96 & 2.78 & 2.83 & 2.75 & 2.83 \\
\hline 6 & 1.61 & 1.50 & 2.02 & 1.77 & 1.85 & 1.87 & 1.77 \\
\hline 7 & 1.51 & 1.58 & 1.55 & 1.50 & 1.52 & 1.54 & 1.53 \\
\hline 8 & 1.94 & 2.34 & 2.01 & 2.22 & 2.13 & 1.91 & 2.09 \\
\hline 9 & 1.99 & 1.77 & 1.52 & 1.72 & 1.75 & 1.81 & 1.76 \\
\hline 10 & 1.68 & 1.61 & 1.53 & 1.58 & 1.64 & 1.61 & 1.61 \\
\hline 11 & 1.66 & 2.01 & 1.83 & 2.11 & 1.72 & 1.71 & 1.84 \\
\hline
\end{tabular}

Table 2. Measured tensile strengths of the samples.

\section{Electrochemical modification of the pore structure of mudstone}

The combination of micro-CT, digital image processing, and three-dimensional reconstruction is a new, simple, and feasible method for the analysis of the pore structures of mudstone. A single micro-CT image was randomly selected from the 1200 slices of the micro-CT section images. The single digital image was processed by image segmentation, binarization, and compression, and new images were generated with different resolutions. When the pixel size of the new image was taken as the pore aperture, the rule for the variation in rock porosity as the pore aperture varied was estimated from the single microCT image. The volume-rendering algorithm of the visualized reconstruction can make the single image the image sequence, and can generate a three-dimensional digital image. The rule for rock porosity variation with variation in the pore aperture was estimated based on the image sequence. 


\subsection{Three-dimensional reconstruction of micro-CT image sequence}

100 micro-CT sections were selected, and the single section processing included image segmentation, binarization, and compression. When processed, the 100 sections were sequenced according to the special algorithm, the micro-CT image sequence and threedimensional data were generated. Three-dimensional digital image of binary was generated by image preprocessing, three-dimensional reconstruction, and three-dimensional visualization. The rule for the sandstone porosity variation with the pore aperture was estimated.

The compressed algorithm of micro-CT is that: the odd line of the source image is reserved on the $X$ coordinate, the even line of the source image is reserved on the $Y$ coordinate, and then the new matrix composed by the reserved odd and even lines generated compressed image. The pixel size of the new image is increased by $100 \%$.

Because the porosity of micro-CT image is based on the gray scale of the image, the image preprocessing is interpolation and image smoothing, not including gray histogram equalization, image harpening and color process. The distance between the layers of the micro-CT single section is one pixel of $1.94 \mu \mathrm{m}$, and the distance value is very small. The interpolation algorithm is the gray interpolation, and the image smoothing algorithm is the Gaussian filter.

Ray casting of the volume rendering algorithm was used in the three-dimensional visualization. The two- dimensional projected image was generated through computing the optic effect on all voxels, and the pore structure of sample was shown.

\subsection{Electrochemical modification of pore structure in mudstone}

After the electromotive force treatment, the three-dimensional digital images of the microCT samples in the anodic and cathodic zone were shown in Fig.4. The relationships

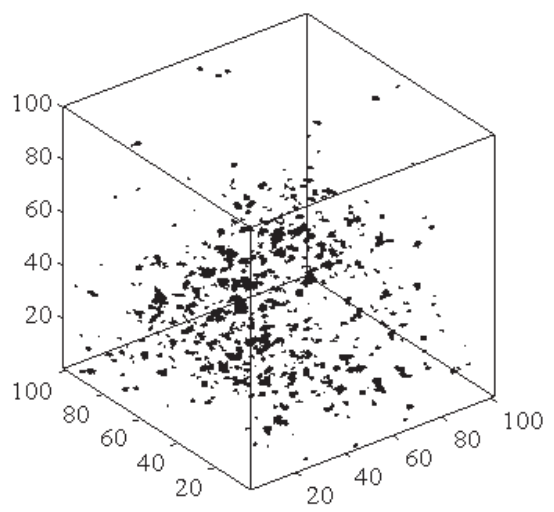

(a)

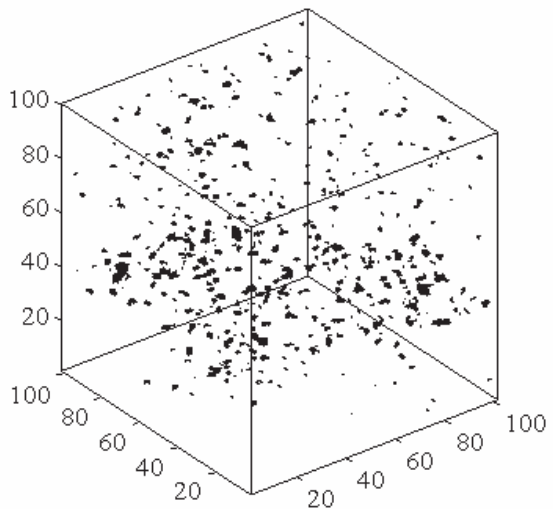

(b) 


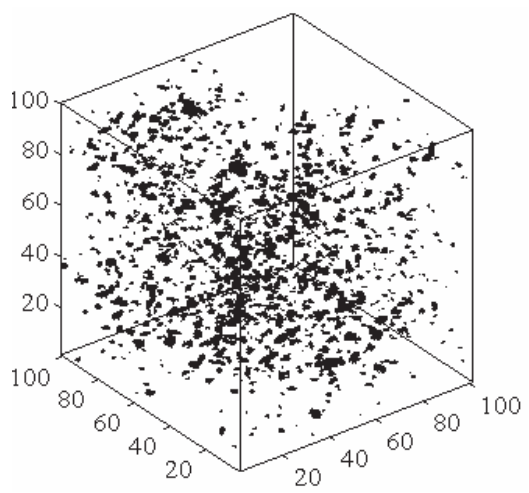

(c)

Fig. 4. Three-dimensional digital images of micro-CT samples: (a) anodic zone; (b) unmodified sample; (c) cathodic zone.

between the variation in sample porosity $(n)$ with variation in pore aperture $(P)$ in the anodic and cathodic zones are shown in Fig. 5. In Fig. 5, the micro-CT image is $2042 \times 2042$ pixels and the pore aperture is $1.02 \mu \mathrm{m}$. After image compression, the new images are $1021 \times$ 1021 pixels, $511 \times 511$ pixels, and $256 \times 256$ pixels, and the pore apertures are $2.04 \mu \mathrm{m}, 4.08$ $\mu \mathrm{m}$, and $8.16 \mu \mathrm{m}$, respectively. As shown in Fig. 5(a), in the anodic zone, the porosity of the electrochemically modified sample is less than that of the unmodified sample. Before the

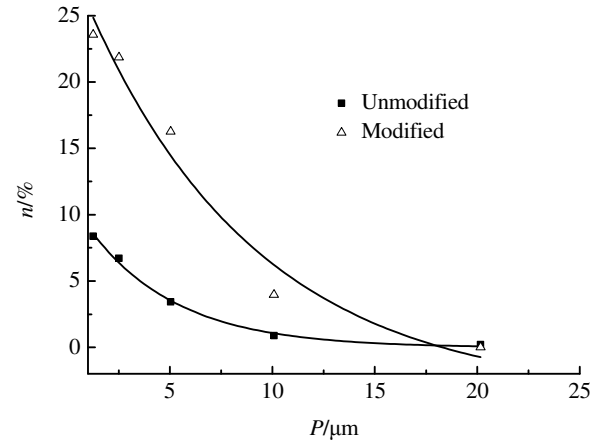

(a)

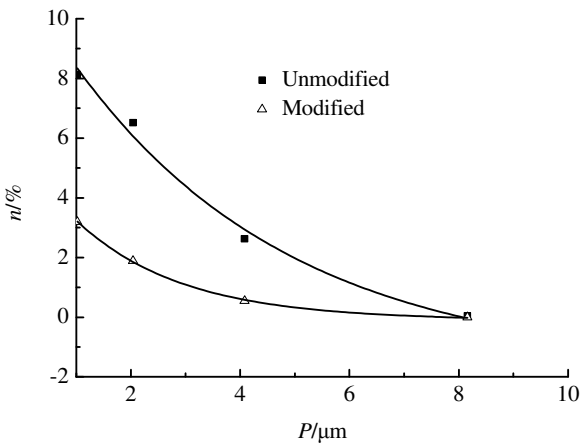

(b)

Fig. 5. The porosity of the sample varies with the pore aperture: (a) anodic zone; (b) cathodic zone.

electrochemical modification, when the pore aperture was $1.02 \mu \mathrm{m}$, the porosity of the sample was $8.13 \%$. The porosity decreased as the pore aperture increased, and when the pore aperture was then $2.04 \sim 8.16 \mu \mathrm{m}$, the porosity was $6.51 \sim 0.04 \%$. After the electrochemical modification, when the pore aperture was $1.02 \mu \mathrm{m}$, the porosity was $3.19 \%$, and when the pore aperture was $2.04 \sim 8.16 \mu \mathrm{m}$, the porosity was $1.89 \% \sim 0$. When the pore aperture was $1.02 \mu \mathrm{m}$, the porosity had decreased by $155 \%$ after electrochemical modification. The relationship illustrated in Fig. 5(a) can be expressed as follows: 


$$
\begin{array}{ll}
\text { Unmodified } & \mathrm{n}=12.99 \exp (-0.25 \mathrm{P})-1.7 \\
\text { Modified } & \mathrm{n}=5.59 \exp (-0.52 \mathrm{P})-0.1
\end{array}
$$

where $\mathrm{P}$ is the pore aperture of the sample and $\mathrm{n}$ is the porosity of the sample. The coefficients of correlation are 0.97 and 0.99 , respectively.

As shown in Fig. 5(b), the micro-CT image was $2001 \times 2001$ pixels and the pore aperture was $1.26 \mu \mathrm{m}$. The compressed images were $1001 \times 1001,501 \times 501,251 \times 251$, and $126 \times 126$ pixels, and the pore apertures were $2.52 \mu \mathrm{m}, 5.04 \mu \mathrm{m}, 10.08 \mu \mathrm{m}$, and $20.16 \mu \mathrm{m}$, respectively. In the cathodic zone, the porosity of the electrochemically modified sample was much higher than that of the unmodified sample. When the pore aperture was $1.26 \mu \mathrm{m}$, the porosity of the unmodified sample was $8.37 \%$, and the porosity decreased as the pore aperture increased, so that when the pore aperture was $2.52 \sim 20.16 \mu \mathrm{m}$, the porosity was $6.71 \sim 0.2 \%$. After electrochemical modification, the pore aperture was $1.26 \mu \mathrm{m}$ and the porosity was $23.57 \%$. When the pore aperture was $2.52 \sim 20.16 \mu \mathrm{m}$, the porosity was $21.84 \% \sim 0$. When the pore aperture was $1.26 \mu \mathrm{m}$, the porosity of the electrochemically modified sample was increased by $182 \%$. The relationship illustrated in Fig. 5(b) can be expressed as follows:

$$
\begin{array}{ll}
\text { Unmodified } & \mathrm{n}=11.54 \exp (-0.23 \mathrm{P})-0.03 \\
\text { Modified } & \mathrm{n}=33.24 \exp (-0.12 \mathrm{P})-3.7
\end{array}
$$

The coefficients of correlation were 0.99 and 0.95 , respectively.

From equations (12), (13), (14), and (15), it can be seen that as the pore aperture increases, the porosities in the anodic and cathodic zones change according to negative exponential rules. Therefore, the porosities of the samples in both the anodic and cathodic zones are altered by the electromotive force treatment, but the negative exponential relationship between the porosity and the pore aperture cannot be changed.

\section{Electrochemical modification mechanism in mudstone}

\subsection{Changes in the mineralogical composition under electromotive force}

Figure 6 shows SEM and X-ray diffraction analyses of mudstone for samples in the anodic and cathodic zones after electromotive force.

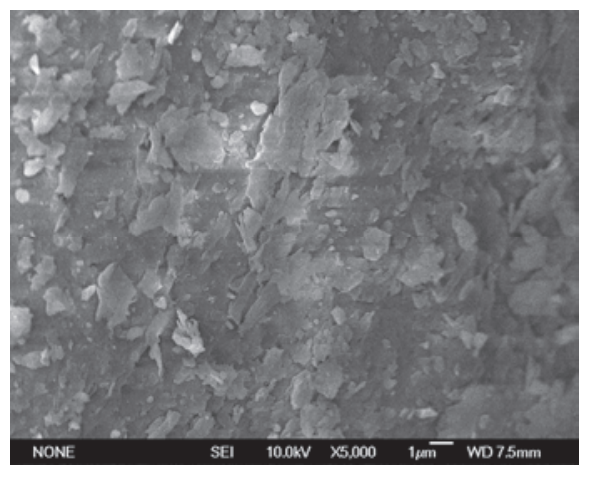

(a)

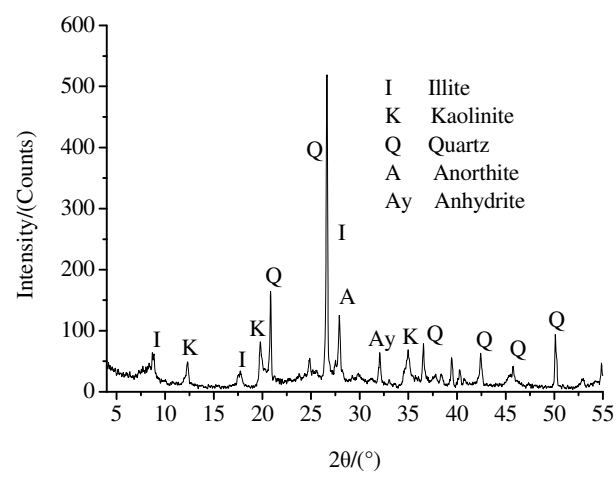

(b) 


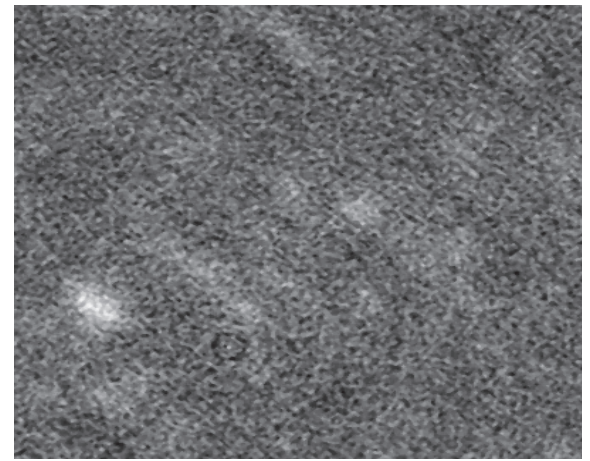

(c)

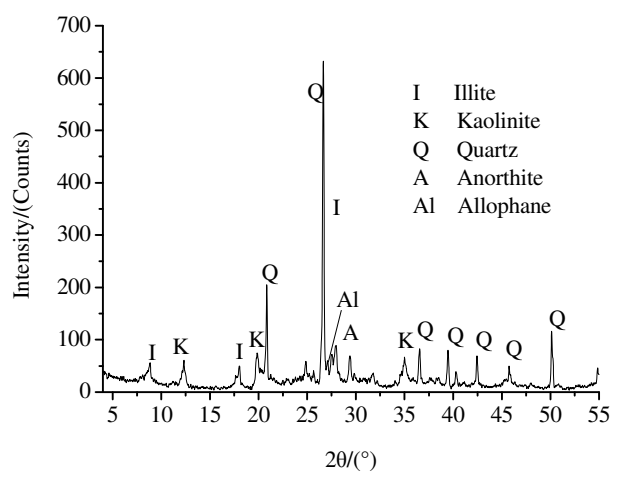

(e)

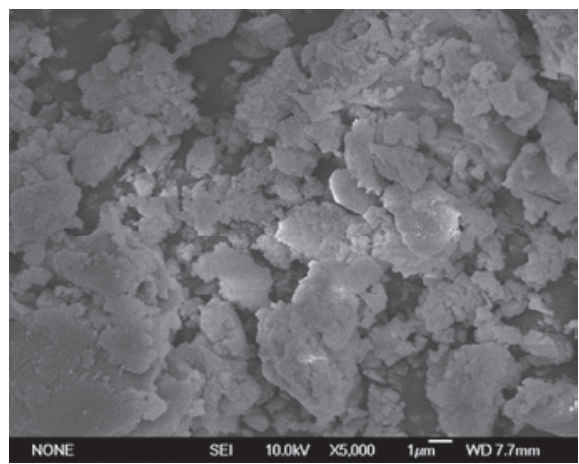

(d)

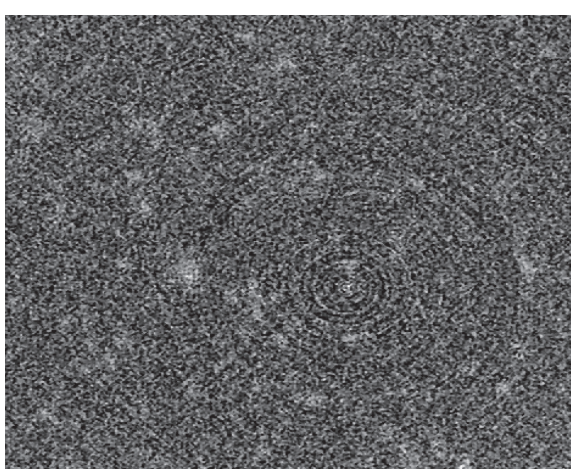

(f)

Fig. 6. SEM, X-ray diffraction and micro-CT analyses: (a), (b) and (c) anodic zone; (d), (e) and (f) cathodic zone.

As shown in Fig. 6(a), the mineralogical composition of the anodic-modified sample changed. The new mineral was allophane, and the main mineralogical composition of the sample was illite $(38 \%)$, kaolinite $(8.8 \%)$, quartz $(30 \%)$, anorthite $(9 \%)$, and allophone $(14.2 \%)$. As shown in Fig. 6(e), in the cathodic zone, the new mineral was anhydrite and the main mineralogical composition of the sample was illite $(40 \%)$, kaolinite $(7.6 \%)$, quartz $(30 \%)$, anorthite $(10 \%)$, and anhydrite $(12.4 \%)$.

Modification of structures and properties with respect to illite, it has a significant change under the action of electromotive force with addition of the electrolyte solutions. X-ray diffraction analyses show that the sheet structure of illite was modified. Modification of structures and properties with respect to kaolinite, it has little significant change. Modification of structures and properties with respect to anorthite, it has been destroyed under electromotive force.

\subsection{Analysis of the electrochemical modification mechanism}

According to the mineralogical composition of the sample, the main minerals were clay minerals and silicate minerals. Silicate is a semi-conductor, with an electrical conductivity lower than the electrical conductivity of the electrolyte used for this electrochemical 
treatment. The electrical conductivity of the mudstone mainly depends on the electrical conductivity of the electrolyte in its pores (Jayasekera \& Hall, 2007; Revil et al., 2007). The electrochemical modification of the mudstone is mainly affected by the pore structure of the sample and the osmosis and degree of filling of the electrolyte. Figure 7 shows a schematic drawing of the electrochemical modification mechanism based on the pore structure and the mineralogical composition of the mudstone.

As shown in Fig. 7, after the application of a direct current to the mudstone, the electrolyte (E) moves osmotically into the pores and participates in several electrochemical reactions. Electrolysis changes the $\mathrm{pH}$ values within the mudstone. Acidification leads to the decomposition or hardening of the silicates and alumina hydroxide, generating allophane from aluminium hydroxide. Alkalization leads to the precipitation of hydroxides on the surfaces of the clay mineral particles, resulting in the generation of a gelatinous precipitate $(\mathrm{Pr})$ and new vug minerals (V). Changes in the $\mathrm{pH}$ values cause changes in the mineralogical composition, and new minerals are created, such as allophane and anhydrite, which causes changes in the tensile strength of the mudstone.

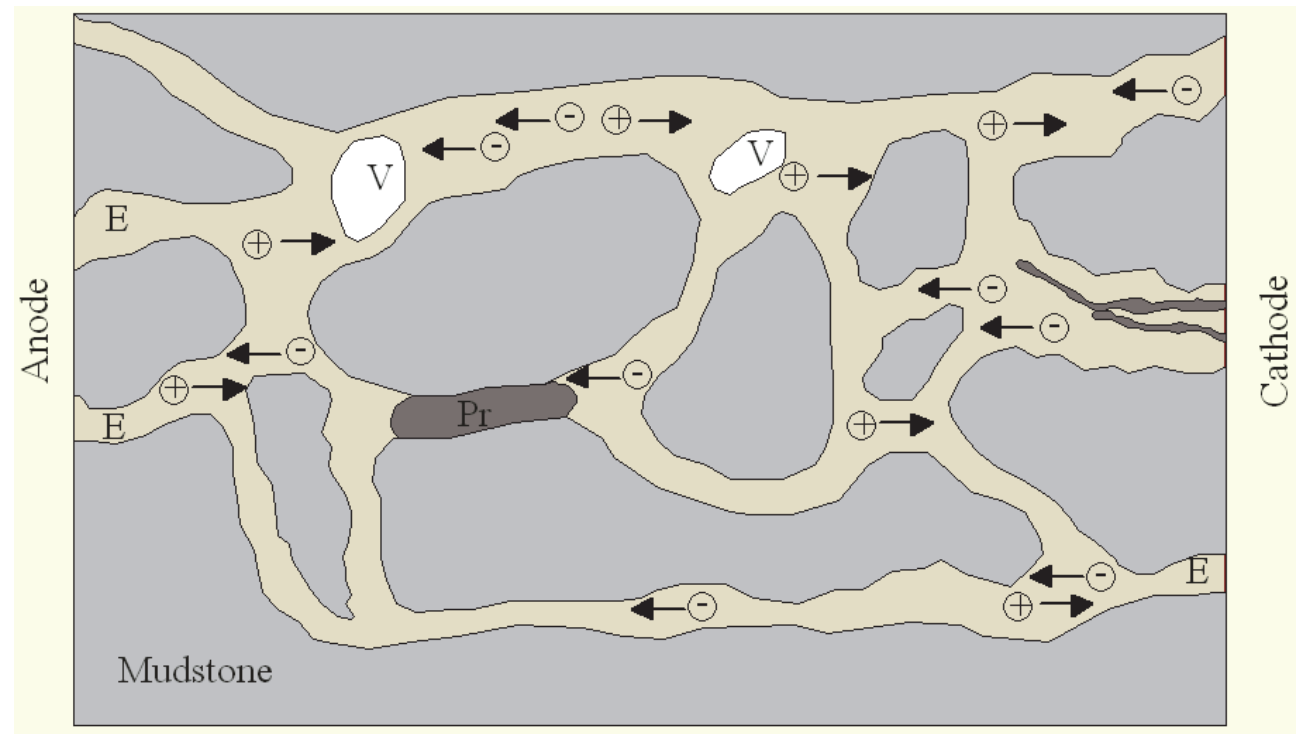

Fig. 7. Schematic drawing of the electrochemical modification of mudstone.

Because of the excess negative charges on the surfaces of the clay mineral particles, the solid particles with negative charges move to the anodic zone and are enriched there by electrophoresis. This causes the fine particles in the pores of the anodic zone to agglomerate and coarsen, so these particles increase in size to fill the pore, causing the porosity to decrease. Electro-osmosis causes the liquid electrolyte, which has a positive charge, to move to the cathodic zone, where it becomes enriched, causing the degree of electro-osmosis to increase. More clay minerals and silicate minerals then take part in the electrolysis, and move toward to the anode. The porosity in the cathodic zone increases.

Electrolysis causes the observed changes in the mineralogical composition of the clay and silicate minerals. Electro-osmosis and electrophoresis cause the observed changes in the 
pore structure, by causing the positively charged liquid electrolyte to move to the cathode, which in turn causes the hydrated layer to decrease, reduces the hydrophilicity, the dehydration, and the consolidation of the anodic zone, increases the intermolecular and hydrogen bond forces, augments the cohesive and interconnection forces, and increases the cementation properties of the clay mineral particles. As a result, the mechanical strength of the mudstone increases.

\section{Conclusion}

Under electromotive force, we performed an experiment in which the mudstone in a coal stratum was electrochemically modified. The tensile strengths of the unmodified and modified samples were evaluated with the Brazilian test. The micro-CT experimental system was used for the non-destructive inspection of the samples in the anodic and cathodic zones. The pore structures in the two zones of the samples were analysed with Matlab. The mineralogical compositions of the samples were analysed, and the electrochemical modification mechanism was proposed based on the pore structure and mineralogical composition of the mudstones. The following conclusions were drawn:

- The mechanism of electrochemical modification is electroosmotic dewatering, stabilization, ionic substitutions, structures, properties change, and forming new minerals.

- This electrochemical method can change the physicomechanical parameters of mudstone, and therefore provides a new way to increase the long-term stability of soft rock, facilitating soft rock engineering.

- Electrochemical modification can improve the mechanical properties of mudstone.

- Digital image processing can calculate the porosity and the pore apertures of the rock. The analysis of micro-CT images showed that as the pore aperture increased, the porosity decreased. In the anodic zone, the modified sample was less porous than the unmodified sample. In the cathodic zone, the modified sample was more porous than the unmodified sample.

- During electromotive force treatment, electrochemical reactions occur in the pores of mudstone. These reactions, which mainly involve electrolysis, electrophoresis, and electroosmosis, cause the mineralogical composition and the pore structure of the mudstone to change. These are the main factors that modify the mechanical parameters of the mudstone.

\section{Acknowledgment}

This research was supported financially by the National Natural Science Foundation of China, grants no. 50474057.

\section{References}

Adamson, L. G.; Quigley, D. W. \& Ainsworth, H. R. (1966). Electrochemical strengthening of clayey sandy soils. Engineering Geology, Vol. 1, No.6, pp. 451-459.

Adamson, L. G.; Rieke, I. I. \& Grey, R. R. (1967). Electrochemical treatment of highly shrinking soils. Engineering Geology, Vol. 2, No.3, (June), pp.197-203. 
Adamson, L. G.; Chilingar, G. V. \& Beeson, C. M. (1996). Electrokinetic dewatering, consolidation and stabilization of soils. Engineering Geology, Vol. 1, No.4, (August), pp. 291-304.

Aggour, M. A. (1992). Muhammadain A M. Investigation of waterflooding under the effect of electrical potential gradient. Journal of Petroleum Science and Engineering, Vol. 7, No.3-4, pp. 319-327.

Aggour, M. A.; Tchelepi, H. A. \& Al-yousef, H. Y. (1994). Effect of electroosmosis on relative permeabilities of sandstones. Journal of Petroleum Science and Engineering, Vol. 11, No.2, (April), pp. 91-102.

Amirat, Y. \& Shelukhin, V. (2008). Electroosmosis law via homogenization of electrolyte flow equations in porous media. Journal of Mathematical Analysis and Applications, Vol. 342, No.2, (February), pp. 1227-1245.

Chilingar, G. V. (1970). Effect of direct electrical current on permeability of sandstone cores. Journal of Petroleum Technology, Vol. 22, No.7, (July), pp. 830-836.

Chukhrov, F. V. (1968). Some Results of the Study of Clay Minerals in the U.S.S.R. Clays and Clay Minerals, Vol. 16, (February), pp. 3-14.

Harton, J. H.; Hamid, S. \& Abi-Chedid. E. (1967). Effects of electrochemical treatment on selected physical properties of a clayey silt. Engineering Geology, Vol. 2, No.3, (June), pp. 191-196.

Jayasekera, S. \& Hall, S. (2007). Modification of the properties of salt affected soils using electrochemical treatments. Geotechnical and Geological Engineering, Vol. 25, No.1, (January), pp. 1-10.

Revil, A.; Linde, N. \& Cerepi, A. (2007). Electrokinetic coupling in unsaturated porous media. Journal of Colloid and Interface Science, Vol. 313, No.1, (January), pp. 315327.

Revil, A. \& Jougnot, D. (2008). Diffusion of ions in unsaturated porous materials. Journal of Colloid and Interface Science. Vol. 319, No.1, (January), pp. 226-235.

Schlocker, J. \& Gray, D. H. (1969). Electrochemical alteration of clay soils. Clay and Clay Minerals, Vol. 17, No.2, (April), pp. 309-322.

Sun, H. (2000). Mechanism and theory study of flowing in porous media under the electric field. MSD Thesis, Xian, Xian Petroleum Institute, China.

Titkov, N. I. (1961). Electrochemical induration of weak rocks, New York, Consultants Bureau, America.

Titkov, N. I.; Petrov, V. P. \& Neretina, A. I. (1965). Mineral formation and structure in the electrochemical induration of weak rocks. New York, Consultants Bureau, America.

Wang, D.; Kang, T. H. \& Chai, Z. Y. (2009). Experimental studies on subsidence and expandability of montmorillonitic soft rock particles under electrochemical treatment. Chinese Journal Rock Mechanical and Engineer, Vol. 28, No.9, (September), pp. 1869-1875.

Youell, R. F. (1960). An electrolytic method for producing chlorite-like substances from montmorillonite. Clay Minerals Bull, Vol. 9, pp. 43-47.

Zhuang, Y. F.; Wang, Z. \& Liu, Q. (2005). Energy level gradient theory for electroosmotic consolidation. Journal of Institute of Technology, Vol. 37, No.2, (February), pp. 811. 
Zhuang, Y. F. \& Wang, Z. (2002). Electrokinetic phenomena in soil and their applications. Joural of Hohai University (natural sciences), Vol. 30, No.6, (December), pp. 112115. 


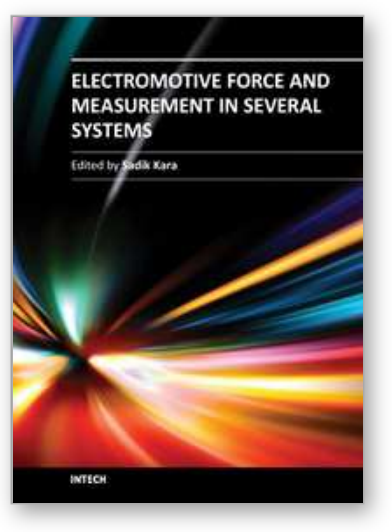

\author{
Electromotive Force and Measurement in Several Systems \\ Edited by Prof. Sadik Kara
}

ISBN 978-953-307-728-4

Hard cover, 174 pages

Publisher InTech

Published online 21, November, 2011

Published in print edition November, 2011

This book is devoted to different sides of Electromotive Force theory and its applications in Engineering science and Industry. The covered topics include the Quantum Theory of Thermoelectric Power (Seebeck Coefficient), Electromotive forces in solar energy and photocatalysis (photo electromotive forces), Electromotive Force in Electrochemical Modification of Mudstone, The EMF method with solid-state electrolyte in the thermodynamic investigation of ternary copper and silver chalcogenides, Electromotive Force Measurements and Thermodynamic Modelling of Electrolyte in Mixed Solvents, Application of Electromotive Force Measurement in Nuclear Systems Using Lead Alloys, Electromotive Force Measurements in HighTemperature Systems and finally, Resonance Analysis of Induced EMF on Coils.

\title{
How to reference
}

In order to correctly reference this scholarly work, feel free to copy and paste the following:

Dong Wang, Jiancheng Song and Tianhe Kang (2011). Electromotive Force in Electrochemical Modification of Mudstone, Electromotive Force and Measurement in Several Systems, Prof. Sadik Kara (Ed.), ISBN: 978-953307-728-4, InTech, Available from: http://www.intechopen.com/books/electromotive-force-and-measurementin-several-systems/electromotive-force-in-electrochemical-modification-of-mudstone

\section{INTECH}

open science | open minds

\section{InTech Europe}

University Campus STeP Ri

Slavka Krautzeka 83/A

51000 Rijeka, Croatia

Phone: +385 (51) 770447

Fax: +385 (51) 686166

www.intechopen.com

\section{InTech China}

Unit 405, Office Block, Hotel Equatorial Shanghai

No.65, Yan An Road (West), Shanghai, 200040, China

中国上海市延安西路65号上海国际贵都大饭店办公楼 405 单元

Phone: +86-21-62489820

Fax: +86-21-62489821 
(C) 2011 The Author(s). Licensee IntechOpen. This is an open access article distributed under the terms of the Creative Commons Attribution 3.0 License, which permits unrestricted use, distribution, and reproduction in any medium, provided the original work is properly cited. 